\title{
Políticas de tecnologias na educação: o Programa Paraná Digital
}

\section{Technology policies in education: the Program Paraná Digital}

\author{
Maria Ivete Basniak ${ }^{1}$
}

\begin{abstract}
RESUMO
O objetivo deste trabalho consiste em analisar a trajetória do Programa Paraná Digital e alguns de seus resultados em escolas públicas estaduais. Para isso, buscou-se, através da metodologia de ciclos de políticas, analisar criticamente a política confrontando, na análise dos três contextos (contexto da influência, contexto da produção do texto e contexto da prática), dados coletados em diferentes fontes: inserção profissional da pesquisadora, literatura já produzida sobre o tema e documentos oficiais sobre os programas desenvolvidos no Paraná, acompanhados de entrevistas com os principais atores. Quanto aos resultados do Programa, é possível afirmar que houve modificação do ambiente das escolas, com a ampliação de recursos úteis ao trabalho do professor; contribuição para a pesquisa e desenvolvimento de softwares e hardwares. Além disso, contribuiu para a iniciação de muitos professores no uso de equipamentos informáticos em suas aulas, embora tais formações tenham priorizado o uso dos equipamentos sem promover debates sobre as tecnologias na educação. O Programa Paraná Digital produziu resultados positivos, mas não consolidou a inclusão digital de alunos e professores do estado do Paraná.
\end{abstract}

Palavras-chave: políticas educacionais; Paraná Digital; tecnologias educacionais; ciclos de políticas.

\begin{abstract}
The aim of this paper is to analyze how the Programa Paraná Digital Digital Paraná Program was conducted, and some of its results in public
\end{abstract}

DOI: $10.1590 / 0104-4060.42627$

1 Universidade Estadual do Paraná. União da Vitória, Paraná, Brasil. Campus União da Vitória. Rua Cel. Amazonas, s/nº. Centro. CEP: 84600-000.E-mail: basniak2000@yahoo.com.br 
state schools. For this, we sought through the political cycles methodology to analyze critically the policy confronting, in the analysis of the three contexts (the context of influence, the text production context and the practice context), data collected from different sources: the researcher's professional integration, literature produced on the theme and official documents about the programs developed in Paraná, along with interviews with the main actors. As for the results of the program, it is possible to affirm that there were changes to the environment of schools, with the amplification of useful resources for the teachers' work; contribution for the research and the development of softwares and hardwares. Besides that, they promoted the teachers' initiation in their use of computer equipment in classrooms, although such procedures gave priority to the use of equipments without promoting debates on technology in education. The Programa Paraná Digital produced positive results, but it did not secure the digital inclusion of students and teachers in the state of Paraná.

Keywords: educational policies; Paraná Digital; educational technologies; policies cycles.

\section{Introdução}

Embora o pioneirismo na elaboração de um Programa Nacional de Informática na Educação (ProInfo) seja do governo federal, a criação de um Programa Nacional de Tecnologia na Educação, mantendo a mesma sigla ProInfo - só ocorreu em 2007. Entretanto, no Paraná, um dos estados brasileiros que primeiro buscou outras formas de financiamento pela via da elaboração de projetos apresentados a órgãos internacionais para conquistar recursos financeiros, a aprovação de um projeto financiado pelo Banco Interamericano de Desenvolvimento (BID) possibilitou que a Secretaria de Estado de Educação do Paraná (SEED-PR) criasse, já em 2003, o Programa que ficou conhecido pela denominação Paraná Digital, assumindo a sigla PRD.

Realizar uma análise das influências que levaram à existência do Programa Paraná Digital, identificar reformulações pressionadas pelo contexto da prática e verificar os resultados (efeitos) do Programa para as escolas estaduais paranaenses são as intenções desta pesquisa. 


\section{De onde partimos}

A pesquisa da Raquel de Almeida Moraes (1996) contribuiu para a compreensão de que a trajetória da tecnologia informática no Brasil está estreitamente vinculada à conjuntura política brasileira. A autora destaca que o Brasil, assim como outros países, passou a apresentar um maior interesse e atuar mais efetivamente no desenvolvimento da informática nacional por interesses bélicos, para que não mais ficasse à mercê do controle estrangeiro, sendo o "Projeto 'Brasil Grande Potência', do Regime Militar pós-1964, o que orientou a política de informática na educação brasileira”. (MORAES, 2000, p. 2).

O trabalho de Maria Cândida Moraes (1997) reitera tais questões ao assinalar que a informática entrou na pauta das discussões das políticas educacionais a partir da década de 1970. Desde então, comissões, secretarias, núcleos, ministério, comitês, projetos e programas foram criados. Em 1972, a Comissão de Coordenação das Atividades de Processamento Eletrônico (CAPRE); em 1979, a Secretaria Especial de Informática (SEI); em 1982, o Centro de Informática do MEC (Ministério da Educação) (CENIFOR); em 1983, o Núcleo Interdisciplinar de Informática Aplicada à Educação/Universidade de Campinas (NIED/ UNICAMP) e o Projeto Educação com computador (EDUCOM); em 1985, o Ministério de Ciência e Tecnologia (MCT); em 1986, o Comitê Assessor de Informática na Educação de $1^{\circ}$ e $2^{\circ}$ graus; em 1987, o Projeto Formar; e em 1989, o Programa Nacional de Informática Educativa (PRONINFE).

Em 09 de abril de 1997 foi criado o Programa Nacional de Informática na Educação (ProInfo), pela Portaria nº 522/MEC, com o propósito de disseminar o uso pedagógico das tecnologias de informática e telecomunicações nas escolas públicas de Ensino Fundamental e Médio pertencentes às redes estadual e municipal de educação. Em 2007, por meio do Decreto ${ }^{0} 6.300$, de 12 de dezembro, o ProInfo passou a ser denominado Programa Nacional de Tecnologia Educacional, tendo como objetivos:

I - promover o uso pedagógico das tecnologias de informação e comunicação nas escolas de educação básica das redes públicas de ensino urbanas e rurais;

II - fomentar a melhoria do processo de ensino e aprendizagem com o uso das tecnologias de informação e comunicação;

III - promover a capacitação dos agentes educacionais envolvidos nas ações do Programa; 
IV - contribuir com a inclusão digital por meio da ampliação do acesso a computadores, da conexão à rede mundial de computadores e de outras tecnologias digitais, beneficiando a comunidade escolar e a população próxima às escolas;

V - contribuir para a preparação dos jovens e adultos para o mercado de trabalho por meio do uso das tecnologias de informação e comunicação; e VI - fomentar a produção nacional de conteúdos digitais educacionais. (BRASIL, 2007, p. 1).

A Secretaria de Estado da Educação do Paraná (SEED-PR) inseriu-se no Programa Nacional de Informática na Educação através do Plano Estadual de Informática na Escola (PEIE) já em 1997. Mas foi a partir do ano de 2003, no início de um novo governo estadual, que a valorização da área foi intensificada através do Projeto BRA 03/036, que originou o programa de uso de tecnologias na Educação Básica que ficou conhecido como Programa Paraná Digital (PRD). Da tomada de uma decisão política, pelo então secretário, foi elaborado pela Secretaria do Estado da Educação do Paraná esse projeto específico para investimentos nessa área, via recursos do BID, através do Programa das Nações Unidas para o Desenvolvimento (PNUD).

Conforme documentado, "O PRD objetivou promover a inclusão digital no estado do Paraná e a melhoria da qualidade da educação básica por meio do uso adequado das novas tecnologias da informação e da comunicação". (PARANÁ, 2010, p. 11). Para alcançar tais objetivos, ele foi estruturado a partir de três eixos que previam: a criação de um portal educacional; a ampliação dos Núcleos de Tecnologia da Educação (NTE); e a implantação de laboratórios de informática nas escolas.

A pesquisa aqui apresentada traz uma visão panorâmica do $\mathrm{PRD}$, ao analisar as influências que levaram à sua criação, assinalar as modificações pelas quais passou e buscar resultados (efeitos) que o Programa trouxe/ainda está trazendo para a educação escolar pública no Paraná em tempos de novas tecnologias.

\section{Procedimentos/metodologia}

Para analisar a trajetória do Programa Paraná Digital e alguns de seus resultados (efeitos) buscou-se uma metodologia que abrangesse todo seu percurso, ou seja, desde que o Programa começou a desenhar-se até o momento em que foi colocado em prática. 
Com essa perspectiva, considerou-se apropriado o desenvolvimento de uma "pesquisa crítica sobre políticas educacionais", também denominada de "pesquisa crítica comprometida com a justiça social". (MAINARDES, 2007, p. 27). Nessa abordagem, a pesquisa busca os resultados (efeitos) de uma política, observando como se constituem as relações de igualdade e inclusão, pois os humanos interagem e produzem de forma diferente.

Para isso, a análise do Programa Paraná Digital estruturou-se através da metodologia de ciclos de políticas embasada pela versão apresentada por Bowe e Ball (1992), citada e utilizada por Mainardes (2007, p. 29). Sua descrição é realizada em um ciclo contínuo que contém três contextos principais: o contexto da influência, o contexto da produção do texto e o contexto da prática. Mainardes (2006, p. 50) esclarece que: "Esses contextos estão inter-relacionados, não têm uma dimensão temporal ou sequencial e não são etapas". Daí a expressão "ciclo", pois a política se molda, sofrendo alterações dependendo de fatores que a influenciam em todos os contextos.

Ball (apud MAINARDES; MARCONDES, 2009, p. 304-305) esclarece que é completamente rejeitável tratar a política como algo linear, tomar-se a política como algo "implementável". Como em uma encenação, embora os atores possuam um roteiro a ser seguido (texto da política), na prática é como se ela fosse encenada por diferentes atores, atuando em cenários completamente diferentes, o que leva a consequências muitas vezes imprevisíveis. Dessa forma, Ball (apud MAINARDES; MARCONDES, 2009, p. 304-305) esclarece que o ciclo de políticas constitui-se como método de pesquisa em políticas, pois: "Ele não diz respeito à explicação das políticas. É uma maneira de pesquisar e teorizar as políticas" e não uma forma de escrevê-las, ou seja, de elaborar políticas.

Uma vez que a política não é linear, os contextos levados em consideração também não o são, pois estão interligados, já que a política não é estática e está à mercê daqueles que a colocam em ação. Dependendo do meio em que é praticada, pode tomar caminhos diferentes dos pensados inicialmente e produzir resultados diferentes dos esperados. Dessa forma, muitas vezes o contexto da prática toma forma de uma maneira que é preciso reescrever o texto, passando a constituir um "novo" contexto de influência que terá outro texto a ser colocado em prática, estabelecendo outras estratégias políticas, interferindo na escrita do texto e assumindo o caráter dinâmico que é próprio da política em prática.

Para analisar criticamente a política sob essa ótica, buscou-se confrontar na análise dos três contextos (contexto da influência, contexto da produção do texto e contexto da prática) dados coletados em diferentes fontes:

a) a experiência da pesquisadora, por ter vivenciado grande parte do Programa e ser uma das atoras a encenar o texto da política, primeiro como 
professora da rede estadual e em seguida como assessora pedagógica de uma Coordenação Regional de Tecnologia Educacional (CRTE) do estado;

b) teses e dissertações publicadas na Biblioteca Digital Brasileira de Teses e Dissertações;

c) documentos do Programa de Expansão, Melhoria e Inovação no Ensino Médio (PROEM) e PRD (projetos, pedidos de prorrogação de prazo de financiamentos, relatórios, resoluções e outras publicações governamentais);

d) programas eleitorais gratuitos utilizados na campanha de 2002 contendo propostas educacionais;

e) entrevistas com os principais atores envolvidos nos três contextos do Programa: Secretário da Educação em 2003-2008, Coordenador do Portal Dia a dia Educação em 2003-2007, Coordenadora do PROEM em 2003, assessora pedagógica que acompanhou todos os contextos do Programa 2003-2012. Também foram realizadas entrevistas com atores que trabalham ou estudam em duas escolas de um município do interior do Paraná, para que fosse possível analisar e confrontar opiniões de locais diferentes. Dessas escolas foi também coletada a agenda do laboratório de informática para verificar o seu uso durante quatro semanas do ano de 2013.

\section{Análise}

Entre os principais fatores que levaram à criação e ao desenvolvimento do Programa Paraná Digital podem-se destacar pelo menos três: o descontentamento dos profissionais da educação com as ações do governo anterior em relação à educação; a mudança no governo do estado do Paraná em 2003, com a consequente mudança das pessoas que ocupavam os principais cargos na Secretaria de Estado da Educação; e o saldo do empréstimo firmado com o BID para o PROEM.

O Programa Paraná Digital foi criado após mudanças no governo do estado, que passou da administração do PSDB, havia oito anos consecutivos à frente do estado, ao PMDB; neste cenário a educação era um dos âmbitos mais descontentes com o governo anterior e já vinha com uma agenda repleta de solicitações. Mas, como até aqui mencionado, era um Programa iniciado no governo anterior, que forneceu recursos financeiros para que o Projeto BRA/03/036 se concretizasse.

Dessa forma, o Programa Paraná Digital relaciona-se intrinsecamente com o PROEM, como demonstram os documentos oficiais ligados ao financia- 
mento do PRD. Com exceção do documento intitulado Projeto BRA/03/036, duas revisões substantivas, um relatório apresentado ao PNUD datado de 2009 e um relatório final do Programa, todos os demais documentos (um relatório inicial, quatro relatórios parciais, um relatório final, quatro pedidos de revisão de prazo) são denominados pelo PROEM. O relatório de atividades do PROEM de 2004 destaca que:

Sem dúvida o grande desafio dos policy mankers (sic), da educação dos países da América Latina, é a formulação de políticas e projetos que tornem as escolas e o tempo com a aprendizagem mais atrativo do que seus concorrentes na sociedade contemporânea, tais como os meios de comunicação de massa e outras mídias e o mundo do trabalho, questões colocadas na rediscussão da reforma curricular. (PARANÁ, 2005, p. 8)

Da análise desse documento depreende-se que a SEED considerou que a disponibilização de laboratórios de informática nas escolas incentivaria a aprendizagem dos alunos. Os professores não opinaram sobre essa questão. Das entrevistas com os profissionais das escolas concluiu-se que não houve consulta à comunidade escolar para a elaboração do projeto que disponibilizaria recursos para a implementação do Programa na escola; ou disseram "ao menos que eu lembre não teve", ou ainda "que eu saiba não". Reforça-se que a criação do Programa não contou com a participação direta dos professores e da comunidade escolar; a ideia inicial partiu da vontade do então Secretário da Educação, de que os professores tivessem acesso a fontes atuais de pesquisa para preparar suas aulas.

Considera-se também que, embora o histórico profissional do Secretário da Educação 2003-2008 tenha lhe possibilitado participar ativamente de grupos organizados para refletir sobre possibilidades de superar os problemas educacionais postos na época, a falta de debate com a comunidade escolar sobre o Programa Paraná Digital destoou do discurso democrático. Sabe-se que a consulta à comunidade escolar é um processo que demanda tempo e custo, mas colabora para que ela se sinta parte do processo e não interprete muitas questões apenas como sendo de interesse para desvio de verba, como mencionado pelo professor de Geografia da "Escola Guerreira", ao ser questionado sobre quais considerava serem os interesses do estado ao propor o Programa.

No entanto, considera-se que dificilmente a comunidade escolar fosse solicitar a implantação de tais recursos; até pelo fato do novo governador ter assumido o cargo com uma grande pauta de reivindicações dos educadores, na 
qual nenhum dos itens que integraram o PRD estava listado. Ainda hoje, mesmo já tendo contado com acesso a tais recursos que há muito estão obsoletos nas escolas, eles não são itens que constam nas agendas de reivindicações da educação.

O Projeto BRA/03/036 foi firmado em três pilares: a criação do Portal; a implantação de laboratórios de informática em todas as escolas e colégios do estado do Paraná, com conexão à internet; e a capacitação dos professores para uso dessas tecnologias, que seria viabilizada através da ampliação dos NTE. Portanto, partiu do desenvolvimento de um Portal para uso prioritário do professor, cuja formação para usá-lo seria concretizada nos laboratórios de informática através dos NTE.

Ressalte-se que a internet, ainda incipiente naquela época, figurou como um dos meios considerados importantes para melhorar a qualidade de ensino através de seu acesso em todas as escolas pelo Secretário da Educação (20032008). Realmente, a rede virtual continua sendo um dos meios mais eficazes de acesso à informação atualizada, o que a torna um poderoso instrumento de inclusão e/ou exclusão social. Fornecer o acesso à informação atualizada é uma das formas de diminuir a desigualdade social, mas não a garantia de eliminá-la, visto que além do acesso é necessário avaliar o conteúdo disponível na rede, confrontando dados e analisando a veracidade dos fatos.

No entanto, para que isso se concretize em sala de aula é preciso que o professor seja um avaliador crítico dos conteúdos acessados, para que possa, inclusive, propiciar essa discussão com os alunos. Portanto, é preciso que sua formação seja realmente continuada em serviço, ou seja, deve estar atrelada à sua carreira e à sua rotina profissional. Sabe-se que muitos momentos de formação têm servido para despertar a inquietação do professor, mas não proporcionam condições para que o que é recomendado se concretize em ações a serem desenvolvidas em sala de aula.

$\mathrm{O}$ acesso de todas as escolas a todos os recursos implantados é um dos pontos mais positivos e que merece destaque no Programa analisado, pois o discurso da igualdade de acesso em todas as escolas foi concretizado na prática, havendo o seguinte texto nos documentos oficiais: "[...] igualdade de condições a todos os estabelecimentos no que tange à infraestrutura, tecnologia, capacitação docente e materiais pedagógicos". (PARANÁ, 2003, p. 21). Reitera-se que os recursos do Programa vinham de um financiamento firmado ainda no governo anterior, porém favorecendo apenas as escolas de nível médio.

Progressivamente tornou-se inegável o papel de inclusão digital e social que a internet é capaz de desempenhar ao proporcionar acesso virtual às diferentes e variadas fontes de cultura e informação, alargando amplamente o que seria acessível na forma presencial. Portanto, o fato de fornecer acesso a esses recursos pode ser festejado como uma forma de promover o acesso universal à informação e, portanto, de diminuir as diferenças sociais. 
O que não significa que o Programa Paraná Digital tenha apresentado resultados completamente satisfatórios em relação à promoção da inclusão digital de professores e alunos das escolas públicas paranaenses, ainda que a inclusão digital seja considerada na acepção mais simples do termo, ou seja, como mero acesso aos recursos informáticos. Apesar de laboratórios de informática conectados à internet terem sido instalados em todas as escolas públicas estaduais do Paraná, nem sempre o completo acesso a esses recursos por toda a comunidade escolar foi garantido. Entre os fatores que permitem afirmar isso se destaca o acesso ao laboratório, restrito em algumas escolas a alguns membros da comunidade escolar, por exemplo, ao excluir os alunos do laboratório, sem a presença do professor, como também o bloqueio de muitos sites a todos os usuários.

Em síntese, salientam-se como principais resultados do PRD:

a) consolidou a instalação de laboratórios de informática conectados à internet em todas as escolas públicas do Paraná;

b) estendeu o anel de fibra ótica da Companhia Paranaense de Energia (COPEL) levando conexão de internet a lugares sem acesso a tal tecnologia;

c) apresentou o software livre como uma possibilidade para desvencilhar-se do controle tecnológico dos detentores de poder;

d) evidenciou a importância de ouvir os atores escolares em momentos de tomada de decisões na definição de políticas públicas;

e) viabilizou a independência do estado em relação aos detentores dos meios de produção dos softwares proprietários, uma vez que todo o sistema de hardware e software foi desenvolvido em software livre por uma universidade pública do país, a Universidade Federal do Paraná (UFPR), e pela Companhia de Tecnologia da Informação e Comunicação do Paraná (Celepar), o que serviu também para incentivar o desenvolvimento tecnológico do país e do estado;

f) influenciou programas federais, como a implantação do Portal do Professor, o modelo four head dos multiterminais que se veem atualmente também nos computadores do laboratório do ProInfo Rural, além da influência na criação do Projeto ProInfo pela TV Multimídia;

g) ampliou o número de Núcleos de Tecnologia Educacional e, dessa forma, promoveu a iniciação de muitos professores no uso de equipamentos informáticos em suas aulas, devido às formações terem priorizado o uso dos equipamentos e não terem promovido o debate sobre as tecnologias na educação;

h) criou um Portal educacional para agregar inúmeros recursos didáticos e pedagógicos que facilitaram a busca de professores a esses meios. Mesmo que o Portal precisasse da produção dos professores para se 
consolidar como um ambiente de aprendizagem colaborativa, eles não foram obrigados a executar nenhuma tarefa para a qual não se sentissem preparados;

i) instalou TVs Multimídia em todas essas escolas, o que gerou mudanças no projeto inicial, ainda que o professor não tenha sido ouvido na elaboração do Programa. Assim, as necessidades apresentadas pelo professor, quando a política foi colocada em prática, foram ouvidas pelos responsáveis pelo projeto (tomadores de decisão).

Para Ball, em entrevista a Mainardes e Marcondes (2009, p. 308), o conceito básico que sustenta as relações ligadas à justiça social é o que advém do conceito de poder, uma vez que ele vê "a justiça social através da opressão de poder", assim como entende as "políticas de distribuição e reconhecimento em termos de lutas de poder".

Nessa relação é que se pode analisar o porquê do acesso à internet permitido nas escolas ser limitado e controlado. Muitos sites não podiam ser acessados, estando bloqueados, além de o sistema ser controlado e assim os desenvolvedores e controladores do sistema poderem ter acesso a tudo o que os usuários acessavam. Então, uma dupla face disso pode ser verificada: o fato do acesso ser restrito trouxe mais segurança para que o professor pudesse manusear o sistema, aprendendo a utilizá-lo e também a fazer uso dele com os alunos. O que embora não fosse o objetivo inicial do laboratório - pensado para uso prioritário do professor - passou a ser também empregado pelos alunos, inclusive durante as aulas. Por outro lado, as restrições do sistema não somente afetaram o trabalho dos professores que se viram impossibilitados de instalar qualquer programa nos laboratórios, como também "incentivaram" meios, para que principalmente os alunos procurassem burlar o sistema.

Nesse sentido, prevaleceu a instrução programada, de linha de montagem (BUENO, 2013), devido aos usuários terem acesso apenas àquilo que os que detêm o poder de decisão permitem que tenham, sem considerar suas necessidades, descartando discussões sobre perigos e formas de proteção na rede.

É necessário também assinalar que as capacitações dos professores se restringiam à formação instrumental para uso dos equipamentos, sem possibilitar debates sobre o uso dos novos equipamentos a fim de melhorar realmente a qualidade de ensino nas escolas, objetivo proposto pelo Programa.

Assim, o que se constatou na prática foi a continuidade da reprodução na transmissão de conhecimento, tanto nas capacitações de professores quanto nas aulas do ensino básico. A repetição dos métodos de ensino a que somos submetidos ainda está muito presente, mesmo assumindo que outros podem ser mais eficazes teoricamente, na prática continua-se a reproduzir o formato de repasse de informações. 
Entende-se que a formação de professores ainda precisa de maior atenção, pois embora muito se tenha discutido em relação a essa questão, o assunto ainda é tema de grande relevância para que as tecnologias na educação tragam mudanças na qualidade das aulas que ocorrem nas escolas públicas e para que as tecnologias sejam ferramentas de emancipação dos estudantes e não se constituam como mais um agravante de exclusão social.

É necessário priorizar formações que sejam realmente continuadas e não esporádicas e pontuais, em que a questão pedagógica se sobreponha à técnica. É preciso também proporcionar condições para que os professores possam participar de formações em seu horário de trabalho, motivando seu aperfeiçoamento constante a fim de que reflitam sobre sua prática pedagógica e incorporem o uso de recursos tecnológicos às suas aulas. São necessárias formações que possibilitem reflexão e mudança da prática dos professores e consequente inovação de seu trabalho em sala de aula.

Logo, é necessário rever as políticas para que atendam as deficiências e necessidades da realidade das escolas brasileiras, ouvindo os principais atores envolvidos no processo, e planejando ações conjuntas que possibilitem superar os entraves para que as ações tragam resultados efetivos.

As inúmeras modificações sofridas desde a concepção do PRD evidenciaram que ideias iniciais descartadas foram depois retomadas. Um exemplo disso está na concepção do Portal Dia a Dia Educação, inicialmente pensado para agregar fontes atualizadas a serem disponibilizadas aos professores, pensando em contratar pessoas para realizarem esse trabalho. Essa primeira ideia foi descartada a partir do momento em que se passou a considerar o professor da Educação Básica como produtor de conhecimento, capaz de compartilhar na rede suas experiências de sala de aula. Porém, esses Objetos de Aprendizagem Colaborativa $(\mathrm{OAC})$ não obtiveram o sucesso pretendido em relação às suas publicações, apresentando muitos complicadores que acabaram por desestimular os professores a esse tipo de produção.

Ser produtor de conteúdos, compartilhando virtualmente experiências com outros professores, era algo a que os educadores não estavam acostumados e gerou dificuldades, requerendo conhecimentos e uma linguagem que não estavam acostumados a utilizar. Escrever para outro professor era diferente de escrever para o aluno. E ao ser convidado a compartilhar e divulgar conhecimento, ficava a dúvida ao professor se realmente teria que desenvolver mais aquele trabalho e como aquilo repercutiria em sua carreira. Para incentivar a produção de OAC foi concedida uma pontuação e o professor poderia progredir em sua carreira.

Embora isso fosse apontado pelo governo como um incentivo, para o professor que não estava acostumado a esse tipo de atividade, isso se configurou como mais um fardo, pois teria que providenciar fontes e arrumar tempo 
para essa atividade, não estando claro se essa seria a única forma de conseguir pontuação para progredir na carreira ou se poderia ser substituída por outros meios. Posteriormente, ficou estabelecido que a pontuação da produção de um OAC completo (com os 12 recursos) era equivalente a um curso de 60 horas. Como o professor ainda estava mais acostumado a realizar capacitações e por haver muitos problemas de validação de conteúdo, os OAC foram abandonados.

O processo de validação dos OAC demandava um tempo muito grande, pois após enviados para correção, demorava muito para retornarem ao professor, que perdia o incentivo para continuar sua produção. Além disso, muitos problemas técnicos eram encontrados. O Portal já estava em funcionamento e os laboratórios ainda não. Havia dificuldade em realizar formações com os professores para que conhecessem o ambiente e iniciassem suas produções.

Como apontado anteriormente, em 2003, o estado do Paraná saía de um governo com uma outra visão de políticas educacionais. O professor sentia-se muito desvalorizado, por falta de melhoria salarial, em um período sem realização de concursos públicos que gerava instabilidade funcional da maioria dos profissionais e sem perspectivas de incentivos à progressão na carreira profissional. Além disso, as salas de aula estavam superlotadas devido a projetos de aceleração/correção do fluxo, de idade e série, que haviam sido implantados a fim de superar a grande demanda de alunos retidos.

$\mathrm{O}$ insucesso das lutas sindicais com o governo anterior havia levado os professores a se sentirem pressionados a aceitar as decisões governamentais. A supressão pela força de tentativas de mudança colocou os professores em uma posição contraditória. Por um lado, acreditavam que poderiam resgatar seu papel, mas, por outro, entendiam que deveriam se resguardar para não continuarem agregando responsabilidades por problemas educacionais que estavam além de sua capacidade para resolvê-los.

O Portal não havia atingido seus objetivos e acabara por adquirir as características planejadas inicialmente, tornando-se um portal de informações e grande repositório de conteúdos educacionais, mas não de produções dos professores no interior das escolas. Atualmente conta-se com um grande número de conteúdos disponibilizados, porém a maior parte deles existe graças à contratação de empresas para a produção de conteúdos. Posteriormente, houve constituição de uma equipe só para isso, denominada multimeios.

Da necessidade e desejo dos próprios professores, que começaram a demonstrar vontade de compartilhar objetos educacionais com os alunos, mas que não eram possíveis de serem levados para a sala de aula no formato impresso ou apenas com os materiais disponíveis, mudanças foram necessárias. Assim, para que os professores pudessem compartilhar sons, imagens e vídeos com os alunos, levando esses materiais para a sala de aula, foram disponibilizadas 
22 mil TVs 29 polegadas tela plana, que possuíam entrada para dispositivos USB, o que permitiu disponibilizar arquivos nos formatos mp3, jpg, mpeg ou avi. Conforme resultados encontrados nesta pesquisa, esse foi e, apesar dos equipamentos já estarem obsoletos, ainda é um dos recursos mais utilizados pelos professores em sala de aula com os alunos.

Já a TV Paulo Freire contou com tecnologia digital e uma programação exclusiva voltada à educação do Paraná; mesmo assim não conseguiu atingir seu público-alvo. Conforme entrevista, esse recurso surgiu mais do interesse de pessoas ligadas à própria Secretaria da Educação em criá-la, do que da vontade do professor, o que parece ter sido o principal fator para que o recurso não tenha atingido a audiência esperada.

A apreciação dos inúmeros trabalhos de teses e dissertações publicados entre 1998 e 2013 relacionados ao ProInfo, contendo levantamento e identificação dos principais resultados desse Programa federal, evidenciou que apenas disponibilizar equipamentos não é garantia de melhoria na qualidade da educação e nem de que seu uso com finalidade pedagógica se efetive.

O mesmo pode ser evidenciado nos resultados (efeitos) do Programa Paraná Digital. Assim, embora ele tenha buscado formas para incentivar e valorizar o trabalho do professor em sala de aula (disponibilizando recursos a fim de possibilitar fontes atuais de acesso à informação) falhou ao não prever maior participação do professor na definição do projeto, sendo poucos os momentos de discussão e debate em relação às tecnologias na educação, o que permitiria ao professor sentir-se realmente parte do processo educacional.

\section{Conclusões}

Ao retomar o objetivo inicial da análise dos resultados do Programa Paraná Digital nas escolas do estado do Paraná, é possível afirmar que o Programa modificou o ambiente dessas escolas, fornecendo recursos úteis ao trabalho do professor, contribuindo para a pesquisa e o desenvolvimento de softwares e hardwares em uma universidade pública do país (UFPR), com o envolvimento de órgãos estaduais (CELEPAR e COPEL), sendo possível observar suas implicações, inclusive, nos programas federais de tecnologias educacionais.

O PRD ocasionou mudanças no ambiente escolar através da implantação de recursos tecnológicos que, ainda que não fossem de última geração ou tão inovadores quanto se gostaria, anteriormente não faziam parte do cotidiano escolar e, dessa forma, serviram para que o professor começasse a ver outras 
formas de trabalhar o conteúdo. Entretanto, essas outras formas não se apoiaram em novos métodos de ensino, mas, na maioria dos casos, contribuíram para ilustrar o método tradicional. Por exemplo, se antes o professor fazia um desenho no quadro de giz para ilustrar uma explicação, com os novos recursos passou a dispor de uma imagem de melhor qualidade na TV Multimídia para ilustrar sua explicação. Porém, o recurso não foi suficiente para modificar a prática do professor no sentido de usar essa imagem para gerar discussões com os alunos em relação a tal imagem e ao que ela pode representar em relação a determinado conteúdo. Nos cursos para a formação do professor, os novos recursos também não foram discutidos nesse sentido.

Ainda que não seja mensurável em que medida o Programa contribuiu para melhorar a qualidade da educação, pois inúmeros fatores estão relacionados a essa questão, o que se observou é que o Programa contribuiu para inserir muitos professores e não apenas alunos no ambiente informático. Evidencia-se a necessidade de formações dos professores ligadas às tecnologias educacionais integradas às escolas e ao trabalho do professor.

\section{REFERÊNCIAS}

BRASIL. Decreto ${ }^{\circ}$ 6.300. Dispõe sobre o Programa Nacional de Tecnologia Educacional - ProInfo. Diário Oficial da República Federativa do Brasil. Brasília: DF, 13 dez. 2007. Disponível em: <http://www.planalto.gov.br/ccivil_03/_Ato20072010/2007/ Decreto/D6300.htm>. Acesso em: 10 set. 2013.

BUENO, N. L. Tecnologia educacional e reificação: uma abordagem crítica a partir de Marxs e Luckás. Tese (Doutorado em Educação) - Universidade Federal do Paraná, Curitiba, 2013.

MAINARDES, J. Abordagem do ciclo de políticas: uma contribuição para a análise de políticas educacionais. Educação \& Sociedade, v. 94, p. 47-69, 2006. Disponível em: <http://www.scielo.br/pdf/es/v27n94/a03v27n94.pdf>. Acesso em: 13 jan. 2014.

MAINARDES, J. Reinterpretando os ciclos de aprendizagem. São Paulo: Cortez, 2007.

MAINARDES, J. Informações sobre a abordagem do ciclo de políticas. Lista de obras de S. J. Ball e de pesquisas brasileiras que empregam suas ideias. 06 out. 2013. Disponível em: <http://www.uepg.br/gppepe>. Acesso em: 09 nov. 2013.

MAINARDES, J.; MARCONDES, M. I. Entrevista com Stephen J. Ball: um diálogo sobre justiça social, pesquisa e política educacional. Educação \& Sociedade, v. 106, 
p. 303-318, 2009. Disponível em: <http://www.scielo.br/pdf/es/v30n106/v30n106a15. pdf $>$. Acesso em: 25 fev. 2014.

MORAES, R. de A. A política de informática na educação brasileira: do nacionalismo ao neoliberalismo. Tese (Doutorado em História da Educação) - Universidade Estadual de Campinas, Campinas, 1996.

MORAES, M. C. Informática educativa no Brasil: uma história vivida, algumas lições aprendidas. Revista Brasileira de Informática na Educação, v. 1, 1997. Disponível em: $<$ http://www.lbd.dcc.ufmg.br/colecoes/rbie/1/1/003.pdf $>$. Acesso em: 09 out. 2011.

MORAES, R. de A. Informática, educação e história no Brasil. Revista Conecta, v. 3, 2000. Disponível em: $<$ http://www.revistaconecta.com/conectados/rachel historia.htm>. Acesso em: 24 dez. 2012.

PARANÁ. Programa Expansão, Melhoria e Inovação no Ensino Médio do Paraná - Empréstimo $\mathrm{BID} \mathrm{n}^{\circ}$ 0950-oc/BR: proposta de prorrogação dos prazos de comprometimento e de desembolsos dos recursos do empréstimo BID. Curitiba, 2003.

PARANÁ. Programa Expansão, Melhoria e Inovação no Ensino Médio do Paraná: Relatório de Atividades de 2004. Curitiba, 2005.

PARANÁ. Paraná digital: tecnologias de informação e comunicação nas escolas públicas paranaenses. Secretaria de Estado da Educação. Curitiba: SEED/PR, 2010.

PROGRAMA DAS NAÇÕES UNIDAS PARA O DESENVOLVIMENTO. Projeto BRA/03/036 Educação Básica e Inclusão Digital no Estado do Paraná. [200?]. Disponível em: $<$ http://www.pnudbrasil.org.br/projetos/pobreza_desigualdade/visualiza. php?id07=59>. Acesso em: 09 jul. 2013.

Texto recebido em 14 de agosto de 2015. Texto aprovado em 26 de outubro de 2015. 
